\title{
Estimulação elétrica neuromuscular de média freqüência (russa) em cães com atrofia muscular induzida
}

\author{
Medium frequency neuromuscular electrical stimulation (russian) in dogs with induced \\ muscle atrophy
}

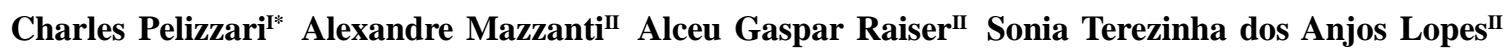 \\ Dominguita Lühers Graça ${ }^{\mathrm{II}}$ Fabiano Zaninni Salbego ${ }^{\mathrm{I}}$ Adriano Tony Ramos ${ }^{\mathrm{I}}$ Rafael Festugatto $^{\mathrm{I}}$ Diego \\ Vilibaldo Beckmann ${ }^{\mathrm{I}}$ Marina Mori da Cunha' ${ }^{\mathrm{I}}$ Rosmarini Passos dos Santos ${ }^{\mathrm{III}}$ Juliana Filipeto \\ Cargnelutti $^{\text {III }}$ Desydere Trindade Pereira ${ }^{\text {III }}$ Tessie Beck Martins ${ }^{\text {III }}$
}

\section{RESUMO}

A estimulação elétrica neuromuscular (EENM) de média freqüência (Russa) ou de Kotz pode ser empregada para a recuperação de massa muscular em animais apresentando atrofia muscular por desuso. Assim, o objetivo deste trabalho foi empregar a EENM de média freqüência no quadríceps femoral de cães com atrofia muscular induzida, avaliando-se a ocorrência de ganho de massa. Foram utilizados oito cães em dois grupos denominados de GI ou controle e de GII ou tratado. Para a indução da atrofia muscular, a articulação fêmoro-tíbio-patelar esquerda foi imobilizada por 30 dias. Após 48 horas da remoção, foi realizada a EENM nos cães do grupo II, três vezes por semana, com intervalo de 48 horas cada sessão, pelo período de 60 dias. Foram avaliadas a mensuração da perimetria da coxa, da goniometria do joelho, as enzimas creatina-quinase (CK) e morfometria das fibras musculares em cortes transversais do músculo vasto lateral, colhido mediante a biópsia muscular. A EENM foi empregada no músculo quadríceps femoral numa freqüência de $2.500 \mathrm{~Hz}$, largura de pulso de 50\% e relação de tempo on/off de 1:2. Não houve diferença significativa quanto aos valores de perimetria da coxa e a atividade da enzima CK entre os grupos I e II. Na goniometria, houve diminuição significativa $(P<0,05)$ da amplitude articular após a remoção do aparelho de fixação externa somente nos animais do grupo II, em comparação a com tempo zero. Quanto à morfometria das fibras do músculo vasto lateral, foram notados valores maiores de área das fibras no grupo Tratado, em relação ao Controle $(P<0,05)$, no dia 90, e, no grupo Tratado, entre os dias zero e 90. A EENM de média freqüência ocasiona hipertrofia do músculo vasto lateral em cães após a atrofia muscular induzida.

Palavras-chave: Corrente de Kotz, EENM, morfometria, cão.

\begin{abstract}
The medium frequency neuromuscular electrical stimulation (NMES) (Russa) or Kotz is designed for recuperation of muscle mass in dogs with muscular atrophy in disuse. This study aims to utilize medium frequency NMES on the femoral quadriceps of dogs with induced muscular atrophy and evaluate the occurrence of gain in mass. Eight dogs in two groups denominated GI, or control, and GII, or treated were used. For the induction of muscular atrophy, the left femoral-tibialpatellar joint was immobilized for 30 days. NMES treatment began 48 hours after the removal of the immobilization device on dogs from group II and was carried out three times per week, with an interval of 48 hours between each session, during 60 days. The following parameters were measured: thigh perimeter, goniometry of the knee, creatine kinase (CK) enzymes and morphometry of the muscular fibers in transversal cuts of the vastus lateralis muscle, collected through a muscular biopsy. EENM was utilized on the femoral quadriceps at a frequency of $2500 \mathrm{~Hz}$, with pulse duration of 50\%, and the time on/off was at a proportion of 1:2. There was no significant difference between the thigh perimeter and the activity of enzyme CK between groups I and II. As for the goniometry a significant increase $(P<0,05)$ was observed among 0 and 30 days after the immobilization in group II. As for the morphometry of the fibers of the vastus lateralis, a significant increase $(P<0,05)$ was observed in the transversal area of the treated group on the $90^{\text {th }}$ day when compared with that observed at the time of immobilization and among the groups, group II presented a greater transversal area $(P<0.05)$ on the $90^{\text {th }}$ day. The medium frequency NMES brings about a hypertrophy of the vastus lateralis muscle in dogs after induced muscular atrophy
\end{abstract}

Key words: Kotz Current, NMES, morphometry, dog.

'Programa de Pós-graduação em Medicina Veterinária, Centro de Ciências Rurais (CCR), Universidade Federal de Santa Maria (UFSM), Santa Maria, RS, Brasil. E-mail: charlespelizzari@yahoo.com.br. *Autor para correspondência.

"Departamento de Clínica de Pequenos Animais, CCR, UFSM, Santa Maria, RS, Brasil.

IIICurso de Medicina Veterinária, UFSM, Santa Maria, RS, Brasil. 


\section{INTRODUÇÃO}

O músculo estriado é uma estrutura envolvida na manutenção e execução dos movimentos do corpo. Ele está em processo constante de remodelagem, podendo ocorrer alterações em seu comprimento e diâmetro (GUYTON \& HALL, 1996). Responde aos diferentes estímulos com alterações bioquímicas, morfológicas e biomecânicas, inclusive quando é imobilizado (APPELL, 1986).

A atrofia muscular pode ocorrer nos casos em que há necessidade de implementação de imobilização para o repouso local após lesões ósseas, musculares, luxações, rupturas ligamentares, (MORRISSEY et al., 1985), como também em outras afecções submetidas ou não à correção cirúrgica (APPEL, 1986). As alterações induzidas pela imobilização, que pode ser definida como um repouso local, contínuo e rígido, não se limitam apenas ao músculo, mas também às estruturas adjacentes, como nervos, vasos sangüíneos, ossos, ligamentos, além de ocasionarem edema e rigidez articular (LOITZ et al., 1989).

A partir de quatro a seis dias de imobilização de um membro, ocorre a perda de proteínas musculares, porém a quantidade de mioglobina permanece inalterada (BOOTH, 1977). Após o sétimo dia, há perda de tecido conjuntivo e também de fibras musculares por área de secção do músculo, promovendo alterações como atrofia muscular e redução da atividade contrátil. Essas alterações ocorrem também durante longos períodos de inatividade muscular (WILLIAMS et al., 1988). Ocorre ainda substituição de miofibras atróficas por células de gordura (McGAVIN, 1998).

Diversos autores utilizaram a imobilização articular e constataram atrofia muscular: MAZZANTI et al. (2004), em cães após artroplastia do joelho, e SALBEGO (2006), em cirurgia de reconstituição de ligamento cruzado cranial em cães. Ambos utilizaram aparelho de fixação externa temporária da articulação fêmoro-tíbio-patelar. No membro pélvico em ratos, JÄRVINEM et al. (1992) e CARVALHO (2001) também observaram diminuição da massa muscular ao empregarem o aparelho gessado como método de imobilização.

A corrente russa ou de Kotz tem sido usada para incremento de força. Consiste em uma corrente de média freqüência de $2.500 \mathrm{~Hz}$ modulada para $50 \mathrm{~Hz}$ (WARD \& SHKURATOVA, 2002). Dessa forma, produz 50 pulsos polifásicos por segundo, implicando durações de pulsos entre 200 e 400 microssegundos, estando esta duração de fase em uma faixa relacionada a estimulação relativamente confortável (NELSON et al., 2003). A escolha da corrente Russa de média freqüência $(2.500 \mathrm{~Hz})$ utilizada nesta pesquisa ocorreu pela limitação de trabalhos em Medicina Veterinária.

O objetivo deste trabalho foi verificar a ocorrência do ganho de massa muscular do vasto lateral, em cães com atrofia muscular induzida, submetido à EENM de média freqüência (Russa) mediante a biópsia muscular e a perimetria da coxa, o efeito da imobilização rígida temporária sobre a articulação fêmoro-tíbiopatelar em ângulo de $90^{\circ}$ através da goniometria e a variação da atividade da enzima creatina quinase (CK) nos cães submetidos à EENM.

\section{MATERIAL E MÉTODOS}

Foram utilizados oito cães, sem raça definida, pesando entre 13 e 25kg, obtidos no Biotério Central da Universidade Federal de Santa Maria. Os animais foram alojados em canis individuais, por um período mínimo de 15 dias para adaptação ao local, recebendo alimentação duas vezes ao dia e água à vontade. Foi administrado anti-helmíntico (pamoato de pirantel/praziquantel) na dosagem de $25 \mathrm{mg} \mathrm{kg}^{-1}$ de peso corporal.

Os animais foram submetidos à anestesia geral com tiopental sódico $\left(12,5 \mathrm{mg} \mathrm{kg}^{-1}\right)$ para estudo radiográfico simples da articulação coxofemoral e fêmoro-tíbio-patelar em incidência crânio-caudal em busca de alterações articulares. Uma vez os cães estando aptos a participarem do experimento, foram distribuídos ao acaso em dois grupos de igual número, denominados de I ou Controle (GI) e II ou Tratado (GII).

Os procedimentos cirúrgicos empregados nestes animais foram compreendidos por biópsia do músculo vasto lateral e imobilização rígida temporária da articulação fêmoro-tíbio-patelar. Para isso, cada animal foi submetido à tricotomia da coxa direita e prémedicados com sulfato de morfina ( $1 \mathrm{mg} \mathrm{kg}^{-1}$ ) associado a maleato de acepromazina $\left(0,05 \mathrm{mg} \mathrm{kg}^{-1}\right)$. A anestesia foi induzida com propofol $\left(4,0 \mathrm{mg} \mathrm{kg}^{-1}\right)$ e mantida com halotano vaporizado em oxigênio a $100 \%$. A analgesia transoperatória foi assegurada com cloridrato de fentanila $\left(0,002 \mathrm{mg} \mathrm{kg}^{-1}\right)$. A anti-sepsia do campo operatório foi realizada com álcool-iodo-álcool e administrada ampicilina sódica (20 $\mathrm{mg} \mathrm{kg}^{-1}$ ), 30 minutos antes do início da cirurgia.

Para a realização da biópsia, foi localizado o músculo vasto lateral do membro pélvico direito, incisado a pele e a fáscia muscular, introduzido o trépano e, com movimento de rotação e alavanca, foi retirado um fragmento de aproximadamente 7x3 milímetros e fixado em formol tamponado por um período mínimo de 48 horas.

Ciência Rural, v.38, n.3, mai-jun, 2008. 
Para imobilização do joelho, foi efetuada a fixação externa percutânea biplanar ou tipo II, conforme descrito por ARON (1996), mantendo-se a articulação numa angulação de $90^{\circ}$, medida com o auxílio de um goniômetro. Como barra de conexão entre os pinos, foi utilizada resina acrílica autopolimerizável. Os animais receberam como terapia antiinflamatória cetoprofeno $10 \%$ (2mg kg-1), por via subcutânea, durante três dias. A ferida de pele, feita durante a biópsia muscular, foi higienizada com solução salina isotônica e protegida por esparadrapo hipoalergênico. As áreas de inserções dos pinos, na pele, foram higienizadas com solução salina isotônica, protegidas por gaze embebida em solução de nitrofurazona e o aparelho de imobilização recoberto com atadura diariamente até o $30^{\circ}$ dia de imobilização, quando o mesmo foi removido.

Os parâmetros da corrente emitida pelo aparelho de EENM foram freqüência de $2.500 \mathrm{~Hz}$, largura do pulso de $50 \%$, modo sincronizado, com ciclos de estimulação de 12 segundos seguidos por 25 segundos de descanso (relação on:off de 1:2). A rampa de subida (rise) três segundos e descida (decay) do pulso três segundos. A intensidade de corrente foi controlada de acordo com o desconforto do animal ao estímulo (vocalização, inquietude, retirada do membro estimulado). Os músculos estimulados foram os que compõem o quadríceps femoral, ou seja, vasto lateral, vasto medial, vasto intermédio e reto femoral.

Para a realização da EENM, foi feita a tricotomia da coxa direita e anti-sepsia com álcool para remoção da oleosidade e redução da resistência para passagem de corrente elétrica. Dois eletrodos de canais diferentes foram colocados sobre os pontos motores (THOMSON \& BOWEN, 1971) dos músculos vasto medial e vasto lateral e os restantes situados sobre os mesmos músculos, o mais distante possível entre eles, para fechamento de corrente numa disposição diagonal. Foi aplicado gel condutor apropriado de aproximadamente $3 \mathrm{~mm}$ de espessura sob os eletrodos, posicionados conforme a técnica quadripolar (KITCHEN, 2003) e fixados com fita elástica.

Os cães do GII receberam tratamento de EENM de Média Freqüência Russa, três vezes na semana, com intervalo de 48 horas entre as sessões, com duração de 30 minutos cada. As sessões iniciaram 48 horas após a retirada do fixador esquelético até o $60^{\circ}$ dia após remoção. Os cães do GI receberam o mesmo tratamento com o aparelho de EENM desligado.

O procedimento de biópsia muscular foi realizado antes da imobilização, após a retirada (30 dias de pós-operatório) e decorridos 60 dias da remoção do aparelho de fixação. Os fragmentos da biópsia muscular do vasto lateral foram corados por Hematoxilina e
Eosina, efetuando-se estudos morfométricos em corte transversal. Cada lâmina histológica foi fotografada com câmera digital acoplada a microscópio com objetiva de 20X. A imagem obtida foi dividida em vinte partes iguais e mensurou-se a área de secção da fibra muscular, que se localizava no centro de cada divisão, através do programa Alfa Easer FC ${ }^{\circledR}$.

Para a realização da perimetria, foi feita a tricotomia da coxa em ambos os membros, e, com uma fita maleável (em cm), foram marcados três pontos eqüidistantes entre o trocânter maior e o côndilo lateral do fêmur. Para a goniometria dos joelhos, utilizou-se goniômetro universal e foram mensuradas as angulações em flexão e extensão total, obtendo-se o arco de movimento. Esses procedimentos foram realizados nos dias 0 (pré), 30 e 90 dias após imobilização e os valores anotados em protocolos específicos.

Para a avaliação da atividade das enzimas CK, foram coletados $5 \mathrm{~mm}$ de sangue nos dias zero, 30 , 45, 60 e 90 após a remoção do parelho de fixação externa. Com exceção do dia zero, as coletas foram distribuídas em três tempos: antes (T0), duas (T1) e seis (T2) horas após EENM.

Para o cálculo estatístico, utilizou-se análise de variância (ANOVA) de uma via, seguida de teste de comparações múltiplas de Duncan. Todos os resultados foram indicados pela média \pm do Erro Padrão da Média (EPM).

\section{RESULTADOS E DISCUSSÃO}

O método de transfixação externa proporcionou estabilização adequada dos joelhos, impossibilitando os animais do uso funcional do membro pélvico, ocasionando atrofia muscular por desuso nos cães do grupo I $(\mathrm{P}<0,05)$. No grupo II, no entanto, houve diminuição da área de secção transversal entre os dias 0 e 30, porém sem diferença estatística. A perda de massa muscular também ocorreu em cães que necessitaram da imobilização articular após a artroplastia do joelho (MAZZANTI et al., 2004) e na substituição do ligamento cruzado cranial por segmento teno-ósseo homólogo conservado em glicerina a $98 \%$ (SALBEGO, 2006).

Na goniometria foi encontrada diminuição da amplitude articular no joelho direito (operado) nos animais dos grupos I e II, aos 30 dias de pós-operatório, em relação ao dia zero, porém com significância estatística $(\mathrm{P}<0,05)$ somente nos cães do grupo II. Essa diminuição era esperada em ambos os grupos, visto que a mensuração foi realizada logo após a retirada do aparelho de fixação. A amplitude articular, no entanto, foi restabelecida no decorrer dos 60 dias após a 
remoção da imobilização externa, ao contrário do observado por MAZZANTI et al. (2004), quando realizaram imobilização articular após artroplastia do joelho. A imobilização articular numa angulação de $90^{\circ}$ provavelmente contribuiu para a pequena diferença da amplitude articular entre os tempos (0 e 30). Este procedimento foi baseado nos relatos feitos por MILLIS (2004), afirmando que a imobilização em extensão resulta em maior espasticidade muscular, podendo aumentar o tempo de recuperação funcional do membro, resultados estes encontrados por SOUZA et al. (2006), que imobilizaram o joelho em extensão após realizarem artroplastia do mesmo. A imobilização em angulação de $90^{\circ}$ foi utilizada por PELIZZARI \& MAZZANTI (2006) e por SOUZA et al. (2007) e não foi relatada nenhuma rigidez articular por tempo prolongado após análise da goniometria do joelho.

A corrente emitida pelo aparelho aos eletrodos a fim de proporcionar a EENM pode variar de intensidade, sendo recomendada mantê-la sempre próxima do limite tolerável pelo animal. Neste estudo, a intensidade foi aumentada ou diminuída, variando em cada animal, sendo mantida em nível tolerado, sem provocar desconforto, como no caso de o cão querer levantar da mesa ou latir. Esta variação de intensidade do estímulo no decorrer do período de tratamento é necessária para evitar a acomodação do nervo sensorial (STARKEY, 2001), além de possibilitar o recrutamento de um número maior de fibras musculares. Mesmo sendo necessário alterar a intensidade de corrente, como observado nesta pesquisa, nenhum dos cães tratados com EENM demonstraram sinais clínicos de dor ou desconforto. Um dos fatores que favoreceram este resultado foi a localização dos pontos motores, baseada no trabalho de THOMSON \& BOWEN (1971), o que permitiu obter-se, com menor intensidade de corrente, um maior recrutamento de fibras musculares.

Foi notado, neste experimento, que os animais do grupo II, para apresentarem desconforto durante a EENM de média freqüência (corrente Russa $-2.500 \mathrm{~Hz}$ ), necessitavam de uma maior intensidade de corrente, quando comparada à corrente de baixa freqüência (FES) utilizada por PELIZZARI \& MAZZANTI (2006). Isso pode ser explicado pela freqüência da corrente Russa, que permite a passagem dos impulsos elétricos através da pele com menor resistência (impedância), proporcionando estimulação agradável e mais eficiente, por recrutar maior número de fibras musculares (NELSON et al., 2003).

A escolha da corrente Russa de média freqüência $(2.500 \mathrm{~Hz})$ utilizada nesta pesquisa ocorreu pela limitação de trabalhos em Medicina Veterinária. MIKAIL (2006) citou que as fibras começam a contrair- se com uma freqüência de $20 \mathrm{~Hz}$, mas a força máxima de contração está entre 60 e 100Hz. ARMSTRONG et al. (1982) demonstraram que nos músculos que compõem o quadríceps femoral, com exceção do vasto intermédio, predominam as fibras tipo II, ou seja, de contração rápida. Já ENVANGELISTA et al. (2003) relataram que a freqüência ideal para contração destas fibras se encontra entre 50 e $150 \mathrm{~Hz}$. Embora a freqüência escolhida nesta pesquisa fosse de $2.500 \mathrm{~Hz}$, o que possibilitou uma menor impedância na pele durante a EENM, este tipo de corrente tem como características períodos sem a passagem de estímulo com duração de 10 milisegundos (largura de pulso de 50\%), produzindo em torno de 50 pulsos por segundo, ou seja, uma freqüência de repetição de disparo de $50 \mathrm{~Hz}$, o que está dentro do alcance biológico de estímulo, que fica entre 0,1 e $200 \mathrm{~Hz}$.

Quanto à análise de ganho de massa muscular, através da morfometria das fibras, entre os tempos de avaliação, foi observada, nos animais do grupo I, uma diminuição significativa $(\mathrm{P}<0,05)$ aos 30 dias de pós-operatório, quando foram removidos os pinos de transfixação, em relação ao tempo zero, caracterizando uma atrofia muscular por desuso. Aos 90 dias de pós-operatório, foi notado que a área transversal das fibras musculares voltou a aumentar, porém sem diferença estatisticamente significativa em relação ao tempo zero (Figura 1A). Uma das explicações para a ocorrência da recuperação da massa muscular seria o retorno funcional precoce do membro pélvico direito devido ao apoio e à caminhada dos animais durante o seu deslocamento até o laboratório de reabilitação, já que é considerado por MILLIS et al. (2004) como um exercício terapêutico, sendo observado também por SOUZA (2006) e PELIZZARI \& MAZZANTI(2006).

Um estudo realizado por MILLIS (2000), em cães submetidos à reconstituição do ligamento cruzado cranial, revelou recuperação da massa muscular, somente quando os animais retornaram a apoiar o membro ao solo, resultado também observado neste experimento. Dessa forma, sugere-se que o retorno da massa muscular inicial deva-se ao apoio antecipado do membro ao solo, pois se tratavam de animais em que apenas foi realizada imobilização sem nenhuma intervenção na articulação fêmoro-tíbio-patelar, já que SALBEGO (2006) relatou que, de 17 cães operados experimentalmente do ligamento cruzado cranial, apenas $5 \%$ retornaram à função normal do membro sem claudicação ao caminhar e ao correr, findado o tempo de avaliação. Verificou-se diferença estatisticamente significativa $(\mathrm{P}<0,05)$ na morfometria das fibras, no grupo GII, entre os tempos zero (antes da imobilização) 


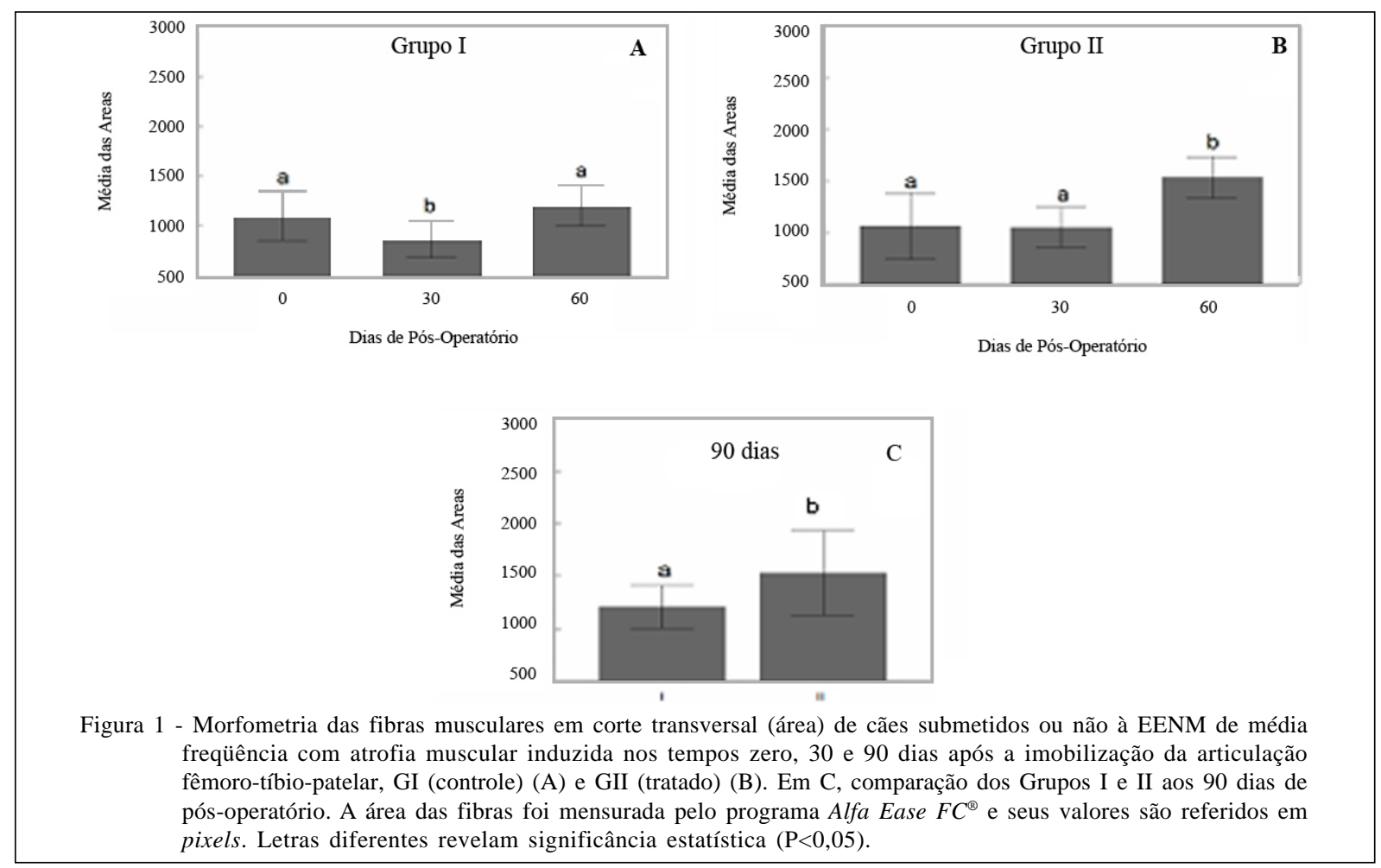

e 90 dias da imobilização articular (Figura 1B) e entre os dois grupos aos 90 dias imobilização (Figura 1C). Isto demonstra que a EENM de média freqüência durante 60 dias promoveu o ganho de massa muscular

A escolha da creatina quinase (CK) foi baseada no trabalho de BIGARD (2001), que citou o aumento da atividade desta enzima quando há fadiga muscular. Já o tempo de coleta foi de acordo com os estudos de CARDINET III (1997), que mostrou que o pico de CK em injúria muscular se dá entre duas a seis horas após a lesão. Neste experimento, a atividade da CK apresentou variações em relação ao tempo de coleta, porém dentro dos valores considerados fisiológicos. POSO et al. (1983) revelaram um aumento da atividade da CK após exercícios acentuados, enquanto que, em trabalhos mais leves, não houve aumentos significativos, sugerindo que a intensidade pode ser um fator importante (SHELLE et al., 1985). Geralmente quando ocorrem lesões musculares por intensidade de exercícios físicos, outros sinais clínicos são observados como dor à palpação (miosite) e às vezes, claudicação. Nesta pesquisa, não foi encontrada nenhuma manifestação clínica de algias musculares durante o tratamento. O principal motivo da ausência de sinais clínicos e do não-aumento significativo da CK que sugerissem fadiga muscular foi a escolha dos parâmetros de EENM, principalmente da relação on time/off time de 1:2, coincidindo com os resultados de
SOUZA (2006), que empregou a mesma proporção de tempo e observou os mesmos resultados.

Quanto à perimetria da coxa para análise do ganho de massa muscular, neste estudo, não houve diferença significativa entre os grupos I e II nos tempos 0, 30 e 90 dias após a remoção do aparelho de fixação, resultado também encontrado por SOUZA (2006). Segundo PELIZZARI \& MAZZANTI (2006), quando se utiliza este tipo de parâmetro, deve-se enfatizar o grau de edema encontrado no membro operado, principalmente no pós-cirúrgico imediato, e, em grau menor, durante o período de imobilização pela presença dos pinos de transfixação, tornando-se subjetivo este tipo de avaliação para conclusão do ganho de massa muscular frente à variação dos valores obtidos. Logo, a análise da área de secção transversal do músculo vasto lateral mostrou-se mais indicada nos estudos em que se utiliza a imobilização rígida temporária da articulação como modelo de atrofia muscular. Já JOHNSON et al. (1997) observaram aumento da perimetria da coxa e retorno funcional do membro em cães submetidos à EENM após a reconstrução do ligamento cruzado cranial.

Neste estudo, foi verificado o aumento semiquantitativo de adipócitos em todos os grupos, em relação ao dia zero. Sugere-se que a presença de adipócitos nas lâminas histológicas possa explicar o aumento da perimetria, quando avaliados dessa forma, 
tornando este método subjetivo, já que McGAVIN (1998) relatou que, ocasionalmente, as miofibras atróficas são substituídas por células de gordura, o que pode tornar o músculo mais desenvolvido, uma condição denominada de pseudo-hipertrofia.

\section{CONCLUSÃO}

De acordo com os resultados obtidos, pode-se concluir que: a EENM de média freqüência ocasiona ganho de massa muscular em cão com atrofia muscular induzida; o aparelho de fixação empregado no joelho em ângulo de $90^{\circ}$, por um período de 30 dias diminui o arco de movimento, o que, contudo, normalizase durante os 60 dias após a remoção do fixador externo; e, por fim, a atividade da CK dos cães submetidos à EENM sofre variação, porém dentro dos valores fisiológicos.

\section{COMITÊ DE ÉTICA E BIOSSEGURANÇA}

Este trabalho seguiu as normas de experimentação segundo o Comitê de Ética Experimental para o uso de animais da Universidade Federal de Santa Maria e foi aprovado, constando no Processo Administrativo número 23081.009802/2006-21.

\section{AGRADECIMENTO}

Ao Conselho Nacional de Desenvolvimento Científico e Tecnológico (CNPq), pelo financiamento da pesquisa, vinculada ao processo 550866/2002-7.

\section{REFERÊNCIAS}

APPELL, H.J. Skeletal muscle atrophy during immobilization. Internal Journal Sports Medicine, v.7, n.1, p.6-12, 1986.

ARMSTRONG, R.B. et al. Distribution of fiber types in locomotory muscles of dogs. American Journal of Anatomy, v.163, n.1, p.87-98, 1982.

ARON, D.N. Tendões. In: BOJRAB, M.J. Técnicas atuais em cirurgia de pequenos animais. 3.ed. São Paulo: Roca, 1996. cap. 40 , p.516-527

BIGARD, A.X. Lesions musculaires induites par léxercice et surentraîntemente. Science \& Sports v.16 p.204-215, 2001.

BOOTH, F.W. Time course of molecular atrophy during immobilization of hinlimbs in rats. Journal of Aplied Physiology. v.43, n.5, p.656-661,1977.

CARDINET III, G.H. Skeletal muscle function. In: KANECO et al. Clinical biochemistry of domestic animals. 5.ed. Academic, 1997. cap.16, p.407-440, 1997.

CARVALHO, C.M.M. Efeitos da imobilização e do exercício físico em algumas propriedades mecânicas do músculo esquelético. 2001. 61f. Dissertação (Mestrado em Interunidades em Bioengenharia) - Universidade de São Paulo.
EVANGELISTA, R.A. et al. Adaptação da característica fisiológica da fibra muscular por meio de eletroestimulação, Fisioterapia Brasil, v.4, n.5, p.326-334, 2003.

GUYTON, A.C.; HALL, J.N. Tratado de fisiologia medica. 9.ed. Rio de Janeiro: Guanabarra Koogan, 1996. 864p.

JARVINEN, M. et al. Effects of the positions of immobilizations upon the tensile proprierties of the rat gastrocnemius muscle. Archives of Physical Medicine and Rehabilitation, v.73, p.253-257, 1992.

JOHNSON, J.M. et al. Rehabilitation of dogs with surgically treated cranial cruciate ligament-deficient stifles by use of electrical stimulation of muscles. American Journal Veterinary Reseach, v.58, p.1473-1478, 1997.

KITCHEN, S. Eletroterapia. Prática baseada em evidência. 11.ed. São Paulo: Manole, 2003. 348p.

LOITZ, B.J. et al. Effects of short-term immobilization versus continuous passive motion on the biomechanical and biochemical proprierties of the rabbit tendon. Clinical Orthopaedics and Related Research, v.244, n.6, p.265-271, 1989.

MAZZANTI, A. et al. Homoimplante ortotópico conservado, associado à terapia soft laser na reparação tenopatelar em cão. Ciência Rural, v.34, n.2, p.429-437, 2004.

McGAVIN, R. Músculos. In: CARLTON, W.W.; McGAVIN, R. Patologia veterinária especial de Thompson. 2.ed. Porto Alegre: ArtMed, 1998. 426p.

MIKAIL, S. Eletroterapia. In: MIKAIL, S.; PEDRO, C.R. Fisioterapia veterinária. São Paulo: Manole, 2006. cap.13, p.96-102.

MILLIS, D.L. Responses of musculoskeletal tissues to disuse and remobilization. In: MILLIS, D.L. et al. Canine rehabilitation \& physical therapy. Missouri: Elsevier, 2004. cap.7, p.113-159.

MILLIS, D.L. et al. Changes in muscle mass following transaction of de cranial cruciate ligament and immediate stifle stabilization. In: CONFERENCE VETERINARY ORTHOPEDIC SOCIETY, 27., 2000. Proceeding... Val d'Isere: Vet and Comp Orthop and Traumat, 2000. p.3.

MORRISSEY, M.C. et al. The effects of electrical stimulation on the quadriceps during postoperative knee immobilization. American Journal of Sports and Medicine, v.13, n.1, p.4045, 1985.

NELSON, R.M. et al. Eletroterapia clínica. 3.ed. São Paulo: Manole, 2003. 578p.

PELIZZARI, C.; MAZZANTI, A. Estimulação elétrica neuromuscular em cães com atrofia muscular induzida. 2006. Capturado em: 20 dez. 2006. On line. Disponível em: $<\mathrm{h} \mathrm{t} \mathrm{t} \mathrm{p} \mathrm{://} \mathrm{w} \mathrm{w} \mathrm{w.} \mathrm{uf} \mathrm{s} \mathrm{m.br/ppg} \mathrm{m} \mathrm{v/s} \mathrm{e} \mathrm{minarios} 2006 /$ Charles_Pelizzari.pdf>.

POSO, A.R. et al. The effect of exercise on blood parameters in standardbred and Finnish-bred horses. Acta Veterinary Scandinavica, v.24, n.2, p.170-184, 1983.

SALBEGO, F.Z. Substituição do ligamento cruzado cranial em cães, por segmento teno-ósseo homólogo 
conservado em glicerina a $\mathbf{9 8 \%}$, submetidos a diferentes protocolos de reabilitação. 2006. 119f. Dissertação (Mestrado em Cirurgia) - Programa de Pós-graduação em Medicina, Veterinária da Universidade Federal de Santa Maria.

SHELLE, J. E. et al. Blood parameters as a result of conditioning horses through short strenuous exercise bouts. In: EQUINE NUTRITION PHYSIOLOGY SYMPOSIUM, 9., 1985. Proceedings... East Lansing: The Equine Nutrition and Physiology and Michigan State University, 1985. p.206.

SOUZA, S.F. Estimulação elétrica neuromuscular em cães submetidos a imobilização rígida temporária da articulação femoro-tibio-patelar. 2006. 84f. Dissertação (Mestrado em Medicina Veterinária) - Universidade Federal de Santa Maria.

SOUZA, S.F et al. Reabilitação em cães submetidos a artroplastia do joelho. Ciência Rural, v.36, n.5, p.1456-1461, 2006.

SOUZA, S.F. et al. Estimulação elétrica neuromuscular em cães submetidos á imobilização rígida temporária da articulação femoro-tibio-patelar. Ciência Rural, v.37, n.1, p.165-170, 2007.

STARKEY, C. Agentes elétricos. In: Recursos terapêuticos em fisioterapia. 2.ed. São Paulo: Manole, 2001. cap.5, p.176-276.

THOMSON, F.K.; BOWEN, J.M. Eletrodiagnostic testing: mapping and clinical use of motor points in the dog. Journal of the American Veterinary Medical Association, v.159, n.12, p.1763-1771, 1971.

WARD, A.R.; SHKURATOVA, N. Russian electrical stimulation:the early experiments. Physical therapy, v.82, n.10, p.1019-1030, 2002.

WILLIAMS, F.A. et al. The importance of stretch and contractile activity in the prevention of connective tissue accumulation in muscle. Journal of Anatomy, v.158, p.109114, 1988. 